\title{
Correlação entre as contagens de reticulócitos manual e automática em amostras de felinos anêmicos
}

\section{[Correlation between manual and automatized values of reticulocyte count in anemic} feline samples]

\author{
S.F. Valle ${ }^{1}$, C.S. Farias ${ }^{2}$, N.C.B. Duda ${ }^{2}$, G. Machado ${ }^{3}$, F.A. Costa ${ }^{1}$ \\ ${ }^{1}$ Universidade Federal do Rio Grande do Sul - Porto Alegre, RS \\ ${ }^{2}$ Médica veterinária autônoma - Porto Alegre, RS \\ ${ }^{3}$ Universidade de Minnesota - Minneapolis, MN
}

\begin{abstract}
RESUMO
O objetivo do presente estudo foi correlacionar os valores de reticulócitos pontilhados e agregados obtidos por metodologia manual com a metodologia automática de contagem de reticulócitos totais em amostras de sangue de gatos anêmicos, analisados em um contador hematológico com citometria de fluxo. Para isso, 40 amostras de sangue de pacientes felinos anêmicos, independentemente de idade e sexo, foram utilizadas para a determinação das contagens absolutas de reticulócitos totais pela metodologia automatizada por citometria de fluxo fluorescente e pela técnica manual com corante supravital, em duplicata. Na contagem manual, houve a discriminação entre reticulócitos pontilhados e agregados. Para a correlação entre os métodos, foi realizada a análise de regressão de Passing-Bablok. A média do hematócrito dos gatos foi de $15,25 \%$, tendo a maioria dos gatos $(32,5 \%)$ apresentado anemia moderada (hematócrito $=17,81 \%$ ). Como resultados, a análise de regressão demonstrou que a correlação entre a contagem absoluta total automática foi superior à contagem manual de reticulócitos agregados $($ rho $=0,71 ; \mathrm{P}<0,001)$ do que a contagem absoluta de reticulócitos pontilhados (rho= 0,68; $\mathrm{P}<0,001)$. Os resultados apresentados sugerem que a contagem de reticulócitos total absoluta realizada pelo analisador hematológico ProCyte Dx em gatos anêmicos se refere à contagem absoluta de reticulócitos. Dessa maneira, recomenda-se que os valores possam ser utilizados para a avaliação imediata da condição hematológica de gatos anêmicos.
\end{abstract}

Palavras-chave: anemia, felino, contagem de reticulócitos, citometria de fluxo

\begin{abstract}
The aim of this study was to correlate the punctate and aggregated reticulocytes values obtained by manual methodology and the automatic reticulocyte count in 40 blood samples from anemic cats. Total reticulocyte absolute counts were determined by automated fluorescence flow cytometry and manual methods in 40 blood samples obtained from anemic cats. The manual count was obtained by supravital stain in duplicate to each sample and the reticulocyte morphology were discriminated between punctate and aggregates reticulocytes. Passing-Bablok regression analysis was utilized to compare the methods. Most samples were from anemic cat $(15,25 \%)$ and the hematocrit mean was 17,81\%. Regression analysis showed that the correlation between the absolute total automatic counts is higher with aggregated reticulocytes (rho $=0,71 ; P<0,001)$ than with absolute punctate reticulocytes counts (rho= $0,68, P<$ 0.001). Results suggest that the ProCyte Dx reticulocytes count in anemic cats is correlated with aggregate reticulocyte count. Thus, the greater amount of RNA and organelles in aggregate reticulocytes generates a cellular complexity and, therefore, greater impregnation of the dye in an automatic count. Thus, the values obtained by the hematologic instrument can be used for the immediate evaluation of the hematological condition in anemic cats.
\end{abstract}

Keywords: anemia, feline, absolute reticulocyte count, flow citometry

Recebido em 7 de julho de 2017

Aceito em 17 de abril de 2018

E-mail: stella.valle@ufrgs.br 


\section{INTRODUÇÃO}

Os reticulócitos são eritrócitos imaturos que possuem retículos compostos por RNA, mitocôndria e organelas, visíveis apenas por meio da coloração das amostras de sangue com corantes supravitais, como o azul de metileno ou o azul de cresil brilhante. Essas células são prematuramente liberadas da medula óssea pelo estímulo da eritropoietina liberada em situações de hipóxia tecidual, como na anemia (Cowgill et $a l .$, 2003). Por esse motivo, a reticulocitose no paciente anêmico indica a habilidade da medula óssea em restabelecer a massa eritrocitária.

A determinação laboratorial dos reticulócitos se baseia na sua aparência quando estes são expostos a corantes supravitais, que provocam a precipitação do RNA de ribossomos e outras organelas, formando um retículo que pode ser visto como um agregado aglutinado de material azul-escuro (reticulócitos agregados) ou como dois ou mais pontilhados pequenos (reticulócitos pontilhados) (Cowgill et al., 2003; Christian, 2010). A contagem manual em microscópio óptico pode apresentar alguns erros analíticos, como maior variação e reprodutibilidade (Reagan et al., 1992), porém ainda pode ser considerada o método padrão-ouro para realizar essa análise (Cowgill et al., 2003).

$\mathrm{Na}$ hematologia veterinária, as contagens celulares automáticas têm sido utilizadas com uma frequência maior, proporcionando resultados mais rápidos e com melhor precisão do que o método manual. Isto se deve ao fato de que, na metodologia automática, aumenta-se o número de células contadas, além de se reduzir a variação entre observadores e de serem evitadas interferências da qualidade da coloração nos resultados, tais como precipitados de corantes e intensidade de coloração (Cowgill et al., 2003). Os instrumentos indicados para o processamento de amostras de animais, que oferecem a tecnologia de citometria de fluxo fluorescente destinados para laboratórios veterinários, como ADVIA (Siemens, Tarrytown, NY, USA), Sysmex XT-2000iV (Sysmex, Lincolnshire, IL, USA) e CELL DYN 3700 (Abbott Diagnostics, Lake Forest, IL, USA), têm custo elevado no Brasil. O ProCyte Dx (Idexx Laboratories, Westbrook, ME, USA) é um contador hematológico que une três tecnologias para a avaliação celular e possui um custo reduzido quando comparado aos demais, favorecendo a utilização em laboratórios, clínicas e hospitais veterinários. Em comparação com o ADVIA 2120, o ProCyte Dx apresentou elevada correlação entre os parâmetros de ambos os contadores (Goldmann et at., 2014). Esse mesmo equipamento demonstrou elevada correlação dos parâmetros em cães, inclusive na contagem de reticulócitos (Fujino et al., 2013).

Na avaliação dos reticulócitos dos felinos, é importante que a contagem automática tenha uma correlação elevada com a contagem de reticulócitos agregados, devido ao seu valor na interpretação da resposta da medula óssea em felinos anêmicos. Com relação à variabilidade, o coeficiente de variação para contagem manual de reticulócitos pode ser de 8 a $23 \%$, enquanto para a citometria de fluxo de contagem pode ser inferior a 3\% (Tvedten, 2010). Uma desvantagem da citometria de fluxo é a possibilidade de contagens celulares falsamente elevadas, causadas pela presença de plaquetas imaturas, corpúsculos de Heinz, corpúsculos de Howell-Jolly, hemácias nucleadas e parasitas sanguíneos (Cowgill et al., 2003).

O objetivo do presente estudo foi verificar a correlação entre os valores de reticulócitos totais obtidos no analisador hematológico ProCyte Dx e os reticulócitos agregados e pontilhados obtidos na contagem manual, em amostras de sangue obtidas de felinos anêmicos.

\section{MATERIAL E MÉTODOS}

Foram utilizadas amostras de sangue encaminhadas ao laboratório para fins de diagnóstico clínico. O objetivo do presente estudo era avaliar a síndrome mielodisplásica em gatos naturalmente infectados pelo vírus da leucemia felina (protocolo de aprovação do Comitê de Ética em Pesquisa da UFRGS $n^{\circ}$ 28928). Foram analisadas as amostras de sangue de 40 gatos anêmicos atendidos no Serviço de Medicina de Felinos (MedFel) do Hospital de Clínicas Veterinárias (HCV-UFRGS), as quais foram encaminhadas para o Laboratório de Análises Clínicas Veterinárias (LACVetUFRGS), no período de junho a novembro de 2015. Todas as amostras foram analisadas em até três horas após a coleta, em tubos com EDTA-K ${ }_{2}$ (etilenoaminotetracético dipotássico). Como critério para a inclusão no estudo, utilizou-se 
valor de hematócrito inferior a $24 \%$ como parâmetro para definição da anemia (Rizzi et al., 2010).

As amostras armazenadas em tubos contendo EDTA- $\mathrm{K}_{2}$ foram analisadas no analisador hematológico automático ProCyte Dx (Idexx Laboratories, EUA), que combina as técnicas de citometria de fluxo, fluorescência óptica e impedância. A técnica se baseia na coloração das células com o corante fluorescente polimetina (Stain Pack Idexx ProCyte Dx, Idexx Laboratories, EUA), que proporciona a ligação aos ácidos nucleicos e é captado pelo aparelho por meio da técnica de fluorescência óptica. Em todas as amostras, foram obtidos valores de eritrócitos, hemoglobina, hematócrito, RDW, porcentagem de reticulócitos corrigida e absoluta, contagem de leucócitos totais e plaquetas. O micro-hematócrito foi realizado como um método de referência para confirmar as variáveis emitidas pelo instrumento.
Para contagem manual de reticulócitos, as amostras de sangue com EDTA- $\mathrm{K}_{2}$ foram diluídas com corante supravital novo azul de metileno, em uma proporção de 1:1, e incubados a $37^{\circ} \mathrm{C}$ durante 15 minutos, em até três horas depois da coleta de sangue. Em seguida, foram realizados novos esfregaços, e estes foram contracorados com corante tipo Romanowsky (panótico rápido). As lâminas foram avaliadas em microscópio óptico em lente de imersão (1000x), em uma área da monocamada com consecutivas 1000 células (Cossandi e Maggiora, 1952; Riley et al., 2001; Cowgill et al., 2003). Os reticulócitos agregados foram considerados como sendo aqueles que apresentaram a precipitação do RNA ribossomal e organelas agregados de cor azul-escuro e os pontilhados aqueles que apresentaram duas ou mais pequenas estruturas pontilhadas (Christian, 2010) (Fig. 1). Todas as amostras foram processadas em duplicata. Em um primeiro momento, foi obtida a porcentagem de reticulócitos, seguida dos cálculos da contagem absoluta e da porcentagem corrigida de reticulócitos.

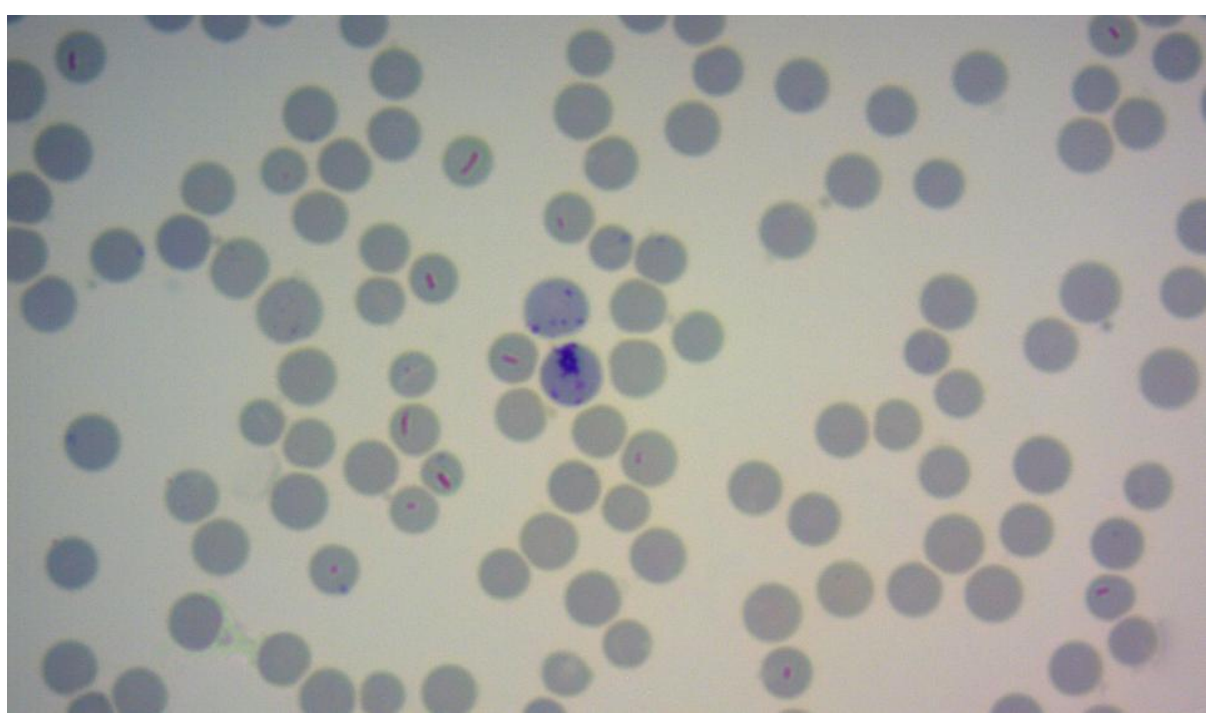

Figura 1. Morfologia de reticulócitos pontilhados (superiores) e agregados (inferiores), em gato moderadamente anêmico (corante: novo azul de metileno, aumento 100x).

Os dados referentes às contagens manuais de reticulócitos (absoluta e corrigida) e à contagem automática pelo equipamento ProCyte Dx (absoluta e corrigida) foram analisados de forma descritiva (valores mínimo, máximo, média e mediana) e posteriormente correlacionados por meio de correlação de Spearman. As demais variáveis hematológicas foram descritas da mesma forma. Em adição, foi realizada a análise de regressão de Passing-Bablok, utilizada para testar a grau de concordância e possível viés entre duas técnicas. Neste caso, utilizou-se como método padrão-ouro o resultado de ProCyte Dx e como método desafio a contagem absoluta de agregados e a contagem absoluta de pontilhados. Como resultado da regressão, foram apresentadas 
as retas de regressão e equações, em que o intercepto representa a constante e o grau de inclinação a medida proporcional de erro medido. A classificação quanto à correlação de Spearman é considerada excelente quando rho $\left(r_{s}\right)=0,93-0,99$; boa: $r_{s}=0,8-0,92$; moderada: $r_{s}=$ 0,59-0,79; e fraca: $r_{\mathrm{s}}=<0,59$ (Papasouliotis et al., 2006).

\section{RESULTADOS}

As 40 amostras de gatos anêmicos selecionados para o estudo incluíram amostras de 20 fêmeas e 20 machos, com idade média de 5,34 anos ( \pm 4,69; idade mínima de três meses até máxima de 21 anos) e com valor de hematócrito médio de 15,25\% (DP= 5,06) (Tab. 1). Quanto à anemia, as amostras selecionadas apresentaram: anemia discreta em 27,55\% (11/40; hematócrito = $20,63 \%)$, anemia moderada em 32,5\% (13/40; hematócrito $=17,81 \%$ ), anemia grave em $17,5 \%$ $(7 / 40$; hematócrito $=11,71 \%)$ e anemia muito grave 22,5\% (9/40; hematócrito $=8 \%)$.

Das 40 amostras analisadas, cinco (12,5\%) apresentaram uma variação entre 11 e $27 \%$ de corpúsculos de Heinz nos eritrócitos, identificados na contagem manual de reticulócitos com corante supravital em microscópio óptico. Com relação à contagem de reticulócitos, na contagem manual e automatizada, as amostras apresentaram variabilidade entre as contagens (Tab. 2).

Tabela 1. Valores de mediana, mínimo, máximo do perfil hematológico de 40 gatos anêmicos atendidos no Hospital de Clínicas Veterinárias - UFRGS

\begin{tabular}{cccc}
\hline Parâmetros & Referência* & Mediana (mín-máx) & Média \\
\hline Eritrócitos $\left(10^{6} / \mu \mathrm{L}\right)$ & $5,5-10,0$ & $3,37(0,96-5,09)$ & 2,9 \\
HG $(\mathrm{g} / \mathrm{dL})$ & $8-15$ & $5,4(2,1-6,7)$ & 4,7 \\
HCT $(\%)$ & $24-45$ & $18(7-22)$ & 15,3 \\
VCM $(\mathrm{fL})$ & $40-60$ & $52,3(39,3-74,1)$ & 53,3 \\
CHCM $(\mathrm{g} / \mathrm{dL})$ & $31-35$ & $31(28-34,6)$ & 31,0 \\
RDW $(\%)$ & $17-22$ & $25,1(19,3-43)$ & 25,6 \\
PLT $\left(10^{3} / \mu \mathrm{L}\right)$ & $200-300$ & $220(5-675)$ & 230,6 \\
\hline
\end{tabular}

Hemoglobina (HG), hematócrito (HCT), volume corpuscular médio (VCM), concentração de hemoglobina corpuscular média (CHCM), RDW (red cell distribution width), plaquetas (PLT). *RIZZI et al., 2010.

Tabela 2. Valores de mediana e média de reticulócitos agregados e pontilhados obtidos pela metodologia manual e de reticulócitos totais obtidos pela metodologia automática em gatos anêmicos

\begin{tabular}{ccc}
\hline Parâmetro & Mediana (mín-máx) & Média \\
\hline Contagem Manual & & \\
Corrigida & $0,12(0-15,49)$ & 1,1 \\
Pontilhados $(\%)$ & $0,02(0-1,71)$ & 0,2 \\
Agregados $(\%)$ & & 73,49 \\
Absoluta & $6,65(0-953,8)$ & 12,58 \\
Pontilhados $\left(\times 10^{3} / \mu \mathrm{L}\right)$ & $1,73(0-101,4)$ & \\
Agregados $\left(\times 10^{3} / \mu \mathrm{L}\right)$ & & 1,9 \\
Contagem Automática & $0,8(0-16,3)$ & 42,39 \\
$\quad$ Corrigida $(\%)$ & $17,55(0,3-272,8)$ & \\
Absoluta $\left(\mathrm{x} 10^{3} / \mu \mathrm{L}\right)$ & &
\end{tabular}

A correlação de Spearman entre a contagem total automática e a contagem absoluta manual, embora tenha sido considerada moderada em relação aos reticulócitos agregados $(\mathrm{rho}=0,71$; $\mathrm{P}<0,001)$ e aos reticulócitos pontilhados (rho= $0,68 ; \mathrm{P}<0,001)$, mostra que a de pontilhados ainda é menor do que a contagem de reticulócitos agregados. Ao se analisar a correlação entre o somatório de reticulócitos agregados e pontilhados absolutos obtidos pelo método manual e a contagem total de reticulócitos no método automático, observou-se também um coeficiente de correlação moderado (rho= 0,69 ; $\mathrm{P}<0,001)$. Este mesmo coeficiente ( $\mathrm{rho}=0,69$; 
$\mathrm{P}<0,001)$ foi observado ao se correlacionar a porcentagem de reticulócitos agregados corrigida da contagem manual com a porcentagem total de reticulócitos do equipamento automático.

A regressão de Passing-Bablok demonstrou maior linearidade e nível de concordância entre a contagem total automática e a manual de reticulócitos agregados (Tab. 3). No caso da contagem de reticulócitos pontilhados, o intervalo de confiança do Slope indica que não há diferença significativa entre os métodos, o que quer dizer que os métodos podem ser utilizados de forma permutável, no caso da determinação de reticulócitos pontilhados. As equações de reta dos dois parâmetros demostram a presença de valores discrepantes e linearidade das medidas (Fig. 2).

Tabela 3. Valores de Rs da correlação entre os valores de contagem manual de reticulócitos e de contagem automática (ProCyte Dx) para amostras de 40 gatos anêmicos atendidos no HCV-UFRGS

\begin{tabular}{cccccc}
\hline Variável & $\mathrm{N}$ & $R s$ & $\begin{array}{c}\text { Slope } \\
\left(\mathrm{CI}_{95 \%}\right)\end{array}$ & $\begin{array}{c}\text { Intercepto } \\
\left(\mathrm{CI}_{95 \%}\right)\end{array}$ & $\begin{array}{c}\text { Bias }\left(\mathrm{CI}_{95 \%} \text { limites de }\right. \\
\text { concordância) }\end{array}$ \\
\hline CRA & 40 & 0,91 & $0,28(0,07-0,38)$ & $-1,08(-2,22-0,11)$ & $0,28(-0,01-0,08)$ \\
CRP & 40 & 0,39 & $1,10(0,79-2,46)$ & $-4,96(-1,04-3,38)$ & $1,10(-0,04-0,22)$ \\
\hline
\end{tabular}

CRA: contagem de reticulócitos agregados; CRP: contagem de reticulócitos pontilhados.
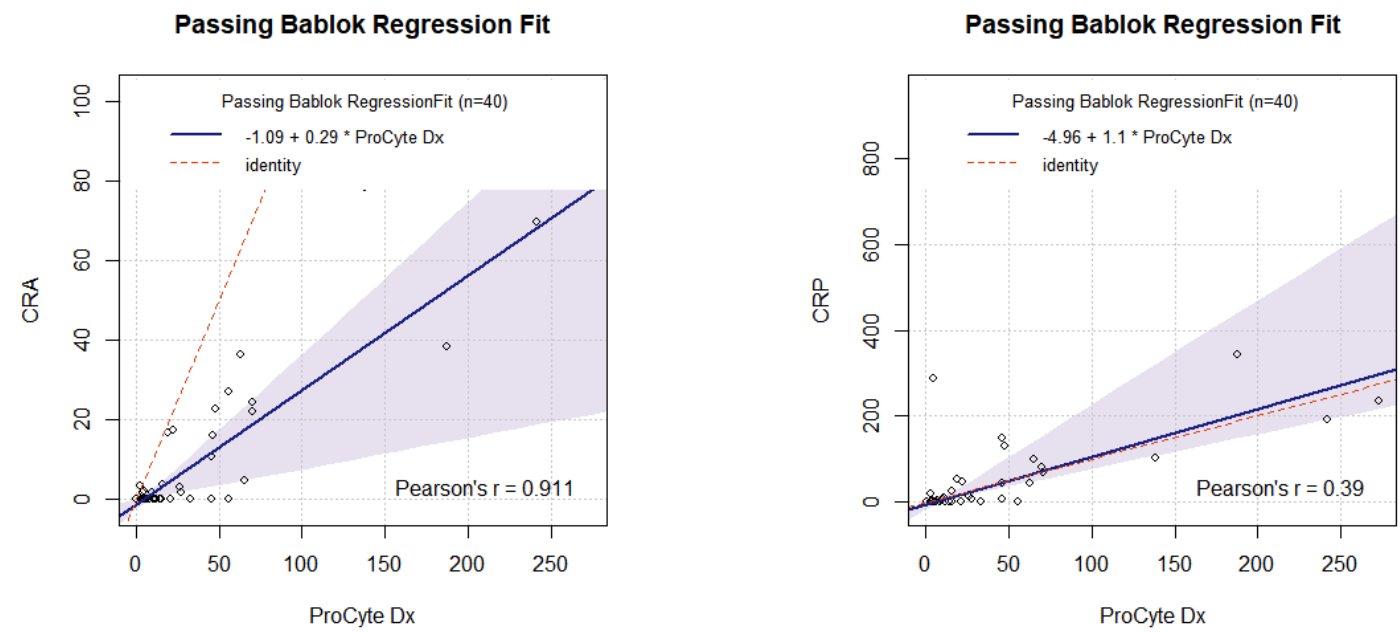

The 0.95-confidence bounds are calculated with the bootstrap(quantile) method

The 0.95-confidence bounds are calculated with the bootstrap(quantile) method

Figura 2. Equações de reta de contagem de reticulócitos agregados - CRA (esquerda) e contagem de reticulócitos pontilhados - CRP (direita).

\section{DISCUSSÃO}

Na determinação da contagem de reticulócitos, embora a metodologia manual em microscópio óptico ainda seja utilizada na maioria dos laboratórios clínicos veterinários por ser uma técnica considerada padrão-ouro, o desenvolvimento de equipamentos automáticos com tecnologia de citometria de fluxo fluorescente também pode fornecer essa análise de maneira eficaz. A avaliação prévia da correlação entre o método manual e o automático com dois equipamentos amplamente utilizados em medicina veterinária (Advia e ProCyte Dx) demonstrou ser boa a moderada para caninos e fraca para gatos (Goldmann et al., 2014). No entanto, esse estudo não considerou os dois tipos de reticulócitos de felinos quando comparados aos reticulócitos totais.

No presente estudo, o coeficiente de correlação moderado entre os reticulócitos agregados e pontilhados com a metodologia automática sugere que a contagem absoluta automática de reticulócitos realizada pelo instrumento em amostras de gatos anêmicos possa ser interpretada como a de reticulócitos agregados. Com esse resultado, pode-se especular que a maior quantidade de organelas nos reticulócitos agregados tenha influência na contagem no 
analisador, uma vez que estas são células mais complexas e com maior impregnação do corante. $\mathrm{O}$ processo de maturação do reticulócito em eritrócito maduro envolve a perda de organelas, a diminuição da síntese de hemoglobina, a perda do receptor de transferrina e corpúsculos de Golgi (Cowgill et al., 2003). Nessa etapa, o RNA torna-se menos denso, mais disperso $\mathrm{e}$ diminuindo em quantidade (Riley et al., 2001), o que proporciona menor fixação do corante e, consequentemente, menor fluorescência será detectada pelo instrumento. Essa constatação já foi sugerida em estudo prévio (Reagan et al., 1992), que observou uma correlação de 0,88 entre a contagem de agregados e a contagem automática.

$\mathrm{Na}$ análise de regressão de Passing-Bablok, embora tenha sido observada associação entre ambos os métodos manuais e o automatizado, a relação da contagem de agregados e o método automático foi ligeiramente superior em comparado à contagem de pontilhados. Nesse sentido, considerando essa análise como método recomendado para identificar a correlação entre técnicas, assume-se que os valores emitidos pelo instrumento em gatos anêmicos sejam de reticulócitos agregados. Essa suposição vem sido justificada pela maior quantidade de organelas nos reticulócitos agregados em comparação aos pontilhados.

Uma das limitações da técnica automatizada para determinação da contagem de reticulócitos é a interferência gerada pela presença de outras estruturas citoplasmáticas que podem erroneamente ser confundidas pelo contador como reticulócitos (Riley et al., 2001). No entanto, tais artefatos podem ser confundidos também na contagem manual, mas são facilmente diferenciados por operadores bem treinados. Gatos hígidos podem apresentar de $1 \mathrm{a}$ 2\% de corpúsculos de Heinz nos eritrócitos, possivelmente devido à maior tendência à oxidação da hemoglobina, já que esta tem o dobro de grupos sulfidrilas reativos quando comparada com a molécula de hemoglobina das outras espécies. Entre as amostras selecionadas para este estudo, cinco $(12,5 \%)$ apresentaram corpúsculos de Heinz visualizados no microscópio óptico durante a contagem manual, o que correspondeu a uma variação de 11 a $27 \%$ dos eritrócitos. Perante a baixa quantidade de amostras com corpúsculos de Heinz, acredita-se que a presença dessas inclusões não tenha ocasionado interferência nos resultados da correlação entre o método manual e o automático.

O presente estudo se baseou na análise de amostras de sangue obtidas de gatos com diversos graus de anemia e, até o presente momento, não foram identificados estudos semelhantes comparando as técnicas de avaliação quantitativa de reticulócitos em felinos.

\section{CONCLUSÕES}

Os resultados apresentados sugerem que a contagem de reticulócitos total absoluta obtida pelo analisador hematológico ProCyte Dx em gatos anêmicos tem maior correlação com a contagem absoluta de reticulócitos agregados obtidos pela metodologia manual. O contador celular automático ProCyte Dx pode ser utilizado nas clínicas veterinárias para avaliação imediata da condição hematológica dos pacientes anêmicos, pois foi capaz de identificar a reticulocitose adequadamente, quando comparado ao método de contagem manual, amplamente utilizado no laboratório clínico veterinário.

\section{REFERÊNCIAS}

CHRISTIAN, J.A. Erythrokinetics and erythrocyte destruction. In: FELDMAN, B.F.; ZINKL, J.G.; JAIN, N.C. (Eds.). Schalm's veterinary hematology. 6.ed. Ames: WileyBlackwell, 2010. p.152-155.

COSSANDI, E.; MAGGIORA, L. Distribution of reticulocytes in blood samples stained with cresyl brilliant blue. Acta Paediatr. Latin., v.5, p.425-429, 1952.

COWGILL, E.S.; NEEL, J.A.; GRINDEM, C.B. Clinical application of reticulocyte counts in dogs and cats. Vet. Clin. N. Am. Small Anim. Pract., v.33, p.1223-1244, 2003.

FUJINO, Y.; NAKAMURA, Y.; MATSUMOTO, H. et al. Development and evaluation of a novel in-clinic automated hematology analyzer, ProCyte Dx, for canine erythrocyte indices, leukogram, platelet counts and reticulocyte counts. J. Vet. Med. Sci., v.75, p.1519-1524, 2013. 
GOLDMANN, F.; BAUER, N., MORITZ, A. Evaluation of the IDEXX ProCyte Dx analyzer for dogs and cats compared to the Siemens ADVIA 2120 and manual differential. Comp. Clin. Pathol., v.23, p.283-296, 2014.

PAPASOULIOTIS, K.; CUE, S.; CRAWFORD, E. et al. Comparison of white blood cell differential percentages determined by the inhouse LaserCyte hematology analyzer and a manual method. Vet. Clin. Pathol., v.35, p.295302, 2006.

REAGAN, W.J.; VAP, L.M.; WEISER, M.G. Flow cytometric analysis of feline reticulocytes. Vet. Pathol., v.29, p.503-508, 1992.
RILEY, R.S.; BEN-EZRA, J.M.; GOEL, R.; TIDWELL, A. Reticulocytes and reticulocyte enumeration. J. Clin. Lab. Anal., v.15, p.267294, 2001.

RIZZI, T.E.; CLINKENBEARD, K.D.; MEINKOTH, J.H. Normal hematology of the cat. In.: WEISS, D.J., WARDROP, K.J. Schalm's veterinary hematology. 6.ed. Ames, Iowa: Wiley-Blackwell, 2010. p.811-820.

TVEDTEN, H. Laboratory and clinical diagnosis of anemia. In: FELDMAN, B.F.; ZINKL, J.G.; JAIN, N.C. (Eds.). Schalm's veterinary hematology. 6.ed. Iowa: Wiley-Blackwell, 2010. p.152-155. 